\title{
Parametric Study of Eddy Current Brakes for Small-Scale Household Wind Turbine Systems
}

\author{
Huiseop Jeong ${ }^{1}$, Hoseong $\mathrm{Ji}^{2, *}$, Sanghyun $\mathrm{Choi}^{3}$ and Joonho Baek ${ }^{4}$ \\ 1 Korea Electric Power Research Institute (KEPRI), Busan 34056, Korea; hyssop.jeong@kepco.co.kr \\ 2 MEMS Technology Centre, Pusan National University, Busan 46241, Korea \\ 3 School of Railroad Engineering, Korean National University of Transportation, Chungju 27469, Korea; \\ schoi@ut.ac.kr \\ 4 Department of Engineering Research, ESCO RTS, Seoul 06134, Korea; jhbaek@enrtech.co.kr \\ * Correspondence: hsji@pusan.ac.kr; Tel.: +82-51-510-2494
}

Citation: Jeong, H.; Ji, H.; Choi, S.; Baek, J. Parametric Study of Eddy Current Brakes for Small-Scale Household Wind Turbine Systems. Energies 2021, 14, 6633. https:// doi.org/10.3390/en14206633

Academic Editor: Frede Blaabjerg

Received: 20 August 2021

Accepted: 2 October 2021

Published: 14 October 2021

Publisher's Note: MDPI stays neutral with regard to jurisdictional claims in published maps and institutional affiliations.

Copyright: (c) 2021 by the authors. Licensee MDPI, Basel, Switzerland. This article is an open access article distributed under the terms and conditions of the Creative Commons Attribution (CC BY) license (https:// creativecommons.org/licenses/by/ $4.0 /)$.

\begin{abstract}
The design and application of eddy current brakes (ECBs) should be simple; further, ECBs should be used semi-permanently. This study aimed to determine major parameters for designing an ECB that can be applied to a small-scale wind turbine generator. To this end, an ECB was developed that could actuate without additional power, thus improving the efficiency of the generator. A series of simulations were conducted for a parametric study to pre-design ECBs suitable for small wind turbines. The six parameters chosen were disk thickness, number of magnets, radial location of magnets from center of disk, magnet pole arrangement, magnetic flux density, and rotational speed. The simulations were conducted on COMSOL Multiphysics. The results indicated that the number of magnets and magnet pole arrangements can significantly affect the performance curve of ECBs. Moreover, the disk thickness and rotational speed are linearly proportional to the braking torque.
\end{abstract}

Keywords: eddy current brake (ECB); wind turbine generator; magnetic flux; braking torque; pole arrangement

\section{Introduction}

Renewable power generation is constantly developing, and small-scale wind power generators are being widely used for household applications owing to the emergence of green growth. To generate wind power, it is obligatory to maintain the rotational speed (approximately 400 RPM for small wind turbines) of the rotor regardless of the wind strength due to mechanical safety reasons and dangers of excess power generation. Therefore, a mechanical friction brake is generally applied to control the rotor speed.

Conventionally, for the friction brake, a part of the generated power should be used to actuate the brakes. This complicates the control system of the brake and lowers the power generation efficiency. In addition, contact of the friction brake between moving parts and stationary braking pads leads to a short lifespan and high resultant maintenance as well as noise. In particular, frequent maintenance is barely achievable for small-scale wind turbines in households.

However, an ECB exhibits a few advantages and offers a viable alternative [1-4] as it can avoid these issues. In contrast to the friction brake, the ECB using permanent magnets does not require additional power consumption or complex control systems. Moreover, the non-contact braking system of ECB increases the lifespan and reduces maintenance. Owing to these advantages, the ECB has been studied by several researchers. Koswatta et al. [2] presented the ability of ECB to control the rotating speed of a wind turbine under varying wind input patterns. However, the distance between magnets and disks was controlled to react braking force if the rotational speed went over a target speed. Jee et al. [3] conducted experimental studies on the effects of distance between a disk and permanent magnets with three low rotational speeds and derived a torque-rotating speed equation at a particular 
distance case. Davies [5] and Gonen [6] conducted experimental and analytical studies on ECBs. Smythe [7], Schieber et al. [8], and Gosline et al. [9] derived equations to estimate the braking torque of ECBs. Wouterse [10] presented a guideline for designing the operational speed range of ECBs corresponding to the critical torque. Recently, as computational power is growing, analytical studies using 3D finite element methods (FEMs) were conducted by Tatis et al. [11], Srivastava and Kumar [12], and Shin et al. [13]. Their analytical results were compared with experimental ones, and no significant differences were observed.

In this work, ECBs were applied to a small-scale wind turbine system, and a 3D FEM analysis was conducted for the early-stage design to find useful design parameters and resultant sensitivity of ECB. The results of a series of simulations conducted for the parametric study to pre-design such ECBs are discussed here. Six parameters, i.e., (1) disk thickness, d, (2) number of magnets, (3) radial location of magnets from center of disk, $\mathrm{m}$, (4) magnet pole arrangement [14], (5) magnetic flux density, B, and (6) rotational speed, $\omega$, were selected. The simulations were conducted using COMSOL Multiphysics [15].

\section{Analytical Procedure}

\subsection{Eddy Current Brake}

ECB is a braking device that uses the dissipated heat generated from eddy currents, which themselves are electric currents induced in a conductive mass and not along a conductive wire when a magnetic field around the mass varies or passes through the magnetic field. Thus, eddy currents are generated following Faraday's law of induction. Their magnitudes and directions are determined according to Ohm's law and Lenz's law, respectively. Eddy currents that occur are eventually dissipated to a form of heat energy. Consequentially, the kinetic energy of the moving object is converted to electric and heat energies, which are eliminated from the moving object, finally causing deceleration.

\subsection{ECB Models}

In designing an ECB, the critical speed [3] must be considered because below this speed, the braking torque is proportional to the rotational speed, but above this speed, the opposite is observed.

Three essential models were developed by Smythe [4], Schieber [5], and Gosline [6] to estimate the braking torque of ECBs. Briefly, Smythe's [4] and Gosline's models [6] simulate the behavior of the torque in the low-speed range, while Schieber's model [5] provides information on the braking torque in the high-speed region. A detailed review can be found here [1]. From these models, the major parameters which affect ECB torque are noted below. For low speeds, Smythe's model [7] is given by:

$$
T=\frac{\omega \sigma S^{2} B_{0}^{2} D^{\prime}}{\left(S+\beta^{2} \sigma^{2} \omega^{2}\right)^{2}} \times n
$$

and Gosline's [9] model by:

$$
T=n \frac{\pi \sigma}{4} D^{2} \delta B^{2} R^{2} \omega
$$

However, according to Schieber's model [8], the braking torque is given by:

$$
T=\frac{1}{2} \cdot \sigma \delta \omega \pi r^{2} R^{2} B_{z}^{2}\left[1-\left\{\frac{\left(\frac{r}{D / 2}\right)^{2}}{\left(1-\left(\frac{R}{D / 2}\right)^{2}\right)^{2}}\right\}\right]
$$

where $\omega$ is the angular velocity, $\sigma$ is the electrical conductivity of a disk, $\mathrm{S}$ is the magnetic reluctance, $B$ is the magnet flux density, $D^{\prime}$ and $\beta$ are complex parameters calculated by the geometry setup [7], $n$ is the number of magnets, $\delta$ is the thickness of a disk sheet, $R$ is the radial location of the magnet, $r$ is the radius of the disk and $D$ is the diameter of (electro) magnet. 


\subsection{Analysis of Variables}

From the models, several parameters are observed to have an effect on an ECB; however, in this study, six parameters, (1) disk thickness, $\delta$, (2) number of magnets, (3) radial location of magnets from center of disk, $m$, (4) magnet pole arrangement [6], (5) magnetic flux density, $B_{z}$, and (6) rotating speed, $\omega$, were selected only to understand the behavior of the ECB under different conditions. Parameters 1,2,3, and 5 are related to the costs down and optimal design of ECB. Parameter 4 is considered to realize the importance of the pole arrangement when designing and assembly ECB. The study of parameter 6 helps to analyze the sensitivity of ECB under operating conditions. The electrical conductivity of the rotating disk and the gap between the magnet and the disk are also important factors affecting the braking torque; however, in this study, pure copper with a fixed electrical conductivity of $5.998 \times 10^{7} \mathrm{~S} / \mathrm{m}$ was considered as the disk material, and the gap was also fixed at $1 \mathrm{~mm}$.

A total of 83 simulations were conducted. To explain each condition briefly, a labeled case structure was defined for each ECB, which is shown in Figure 1. Initially, 72 cases were simulated, and 11 cases were added to match the target maximum torque of a project, $160 \mathrm{~N} \cdot \mathrm{m}$, after initial simulations.

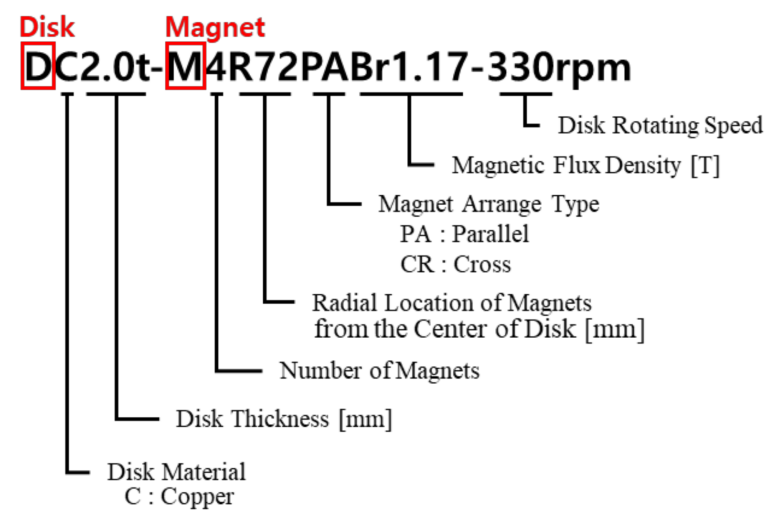

Figure 1. ECB label.

For the initial simulations, cases were combined with each parameter: three disk thicknesses $(2.0,2.5$, and $3.0 \mathrm{~mm})$, four numbers of magnets $(4,6,8$, and 10), two magnet arrangements (parallel and cross arrangement), and three rotational speeds $(330,400$, and $600 \mathrm{RPM}$ ). A magnetic flux density of $1.17 \mathrm{~T}$ and radial location of magnets of $77 \mathrm{~mm}$ were used. For the additional simulations, cases of added magnets $(12,16$, and 20), higher magnetic flux densities ( $3.59 \mathrm{~T}$ and $8.42 \mathrm{~T}$ ), and extended radial location of magnets (92, 122 , and $155 \mathrm{~mm}$ ) were studied.

\section{Computational Methodology}

All cases were calculated using the magnetic and electric field module in COMSOL Multiphysics. The objective of the simulation was to determine key parameters for the ECB design and resultant characteristics.

\subsection{Computational Domain}

The ECB domain used in this analysis was modeled from a test rig, which was used to design an ECB. Figure 2 shows the schematic of the ECB test rig, which was designed to develop a new ECB for a small wind power generator. The test rig consisted of three components: a motor for driving, a torque sensor, and an ECB. In this simulation, a copper disk and a series of magnets were designated as the computational domain without any shaft or jig for simplicity. 


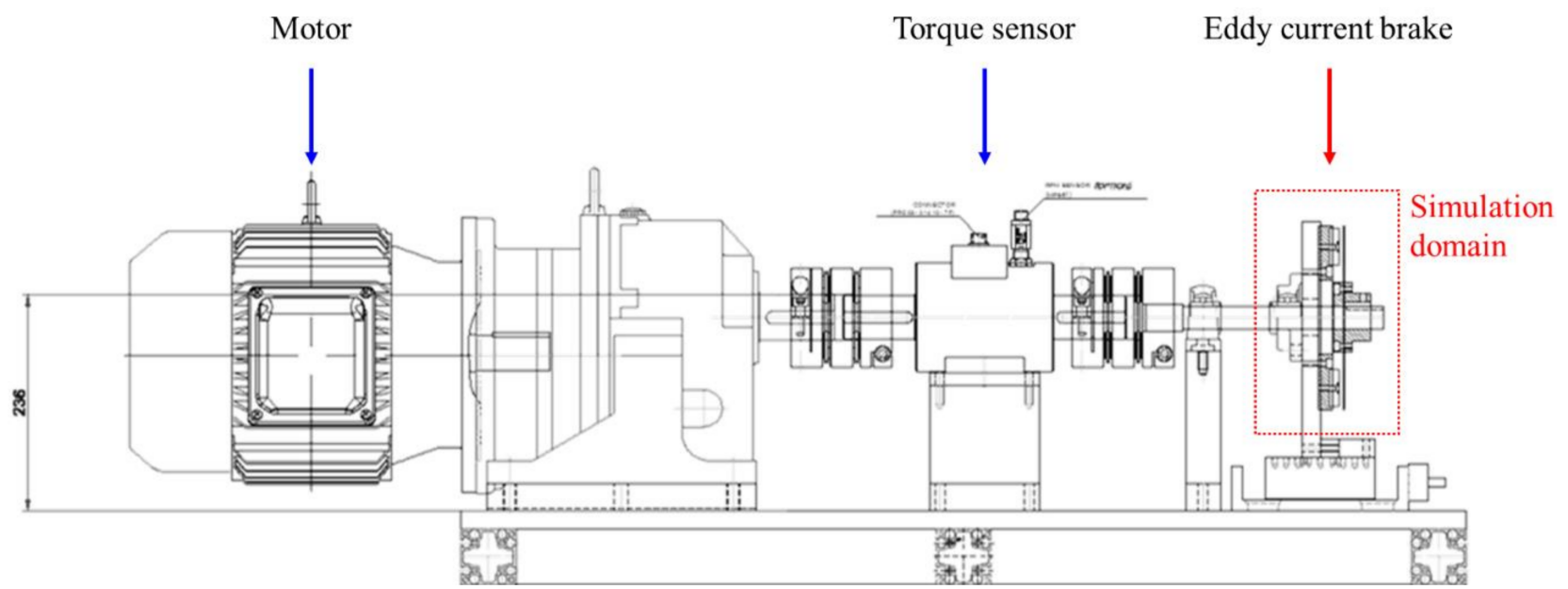

Figure 2. ECB test rig.

Figure 3 shows the computational domain used in COMSOL Multiphysics, which contains a rotating disk, a series of magnets, a sphere space, and the atmosphere. The sphere space was defined as a no-magnetism loss material.

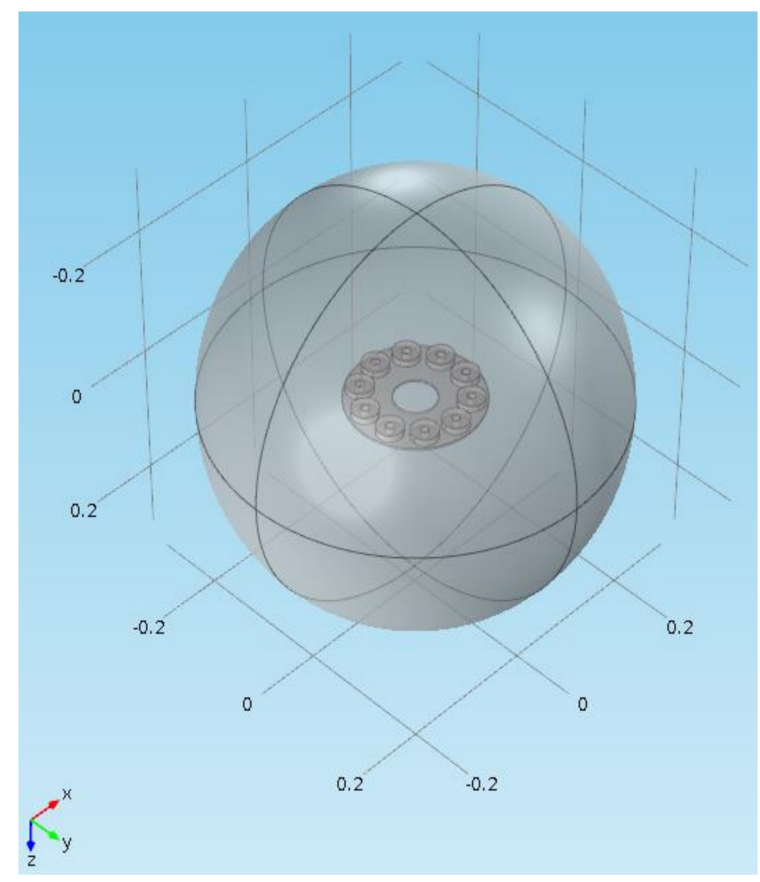

Figure 3. Computational domain in COMSOL.

\subsection{Mesh Sensitivity Study}

The meshes were generated in COMSOL Multiphysics using tetrahedral type elements. Before the simulations were conducted, a mesh sensitivity study was conducted to assess effects the of mesh densities and determine an appropriate mesh setting. The study was conducted using the "DC2.0t-M4R77PABr1.17-330rpm" model, and the details of the mesh sensitivity study are summarized in Table 1 . Figure 4 shows the result of this study. The case of 1,034,768 elements (red point in the chart) was assessed to be the converged mesh size for simulation as the case of 2,919,753 elements has the highest computational time. Based on this result, mesh generation parameters for all simulations were set equally. 
Table 1. Number of elements and domains formed by mesh.

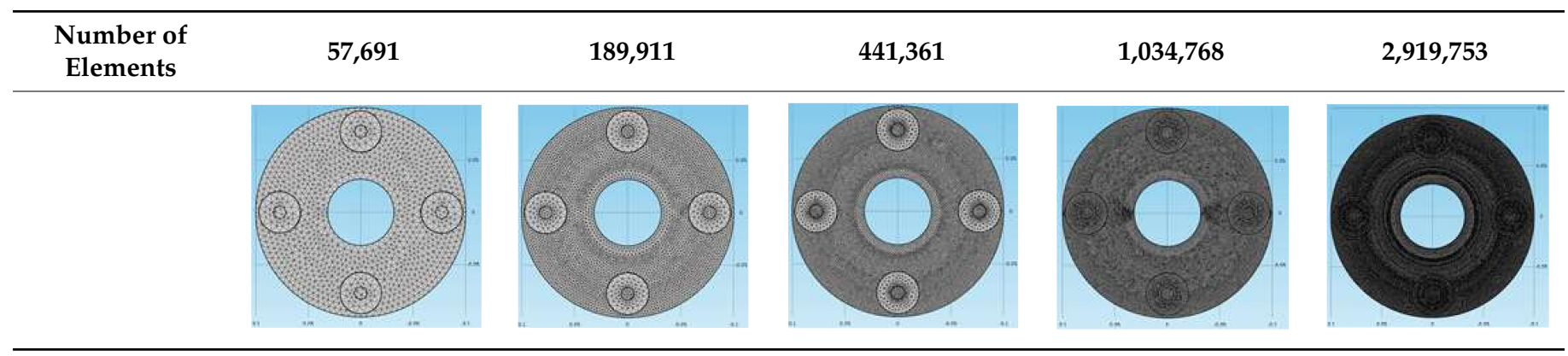

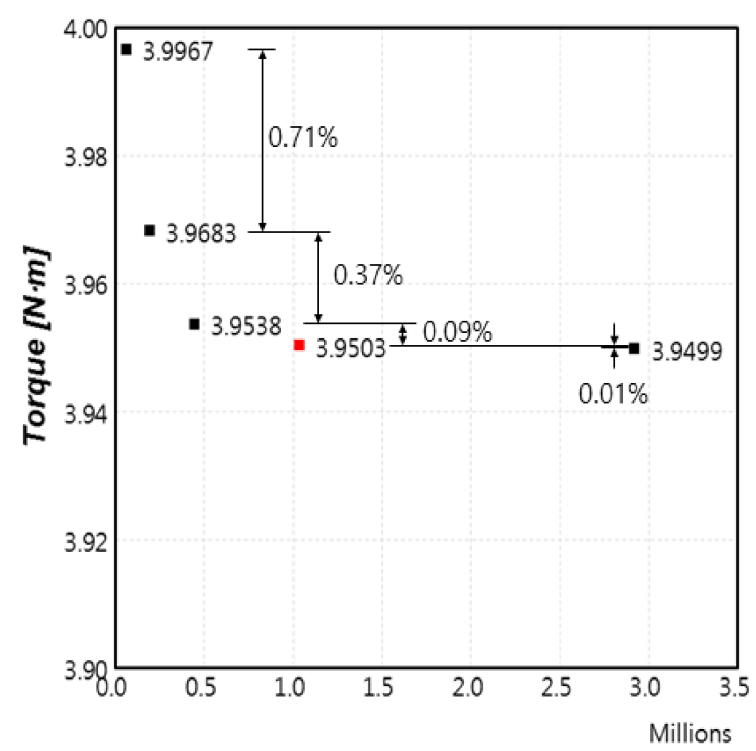

Number of Elements

Figure 4. Torque vs. number of elements plot.

\subsection{Boundary Conditions}

The electrical conductivity and rotational speed of the disk were applied as boundary conditions. The thickness was defined geometrically in the CAD model. An electrical conductivity of $5.998 \times 10^{7} \mathrm{~S} / \mathrm{m}$ was chosen based on pure copper as the COMSOL embedded material. The rotational speed was controlled by setting the angular velocity as the parameter of global definitions and "Lorentz term." Additionally, the density of the disk was also applied to generate a moment of inertia.

For the magnets, the remanent magnetic flux density was used for permanent magnets. To change the magnet arrangement, a positive or negative direction of magnetic flux was used.

A steady-state analysis of the simulation was assumed. Note that heat generation and resultant change of the electrical conductivity of the disk were not considered.

\section{Results and Discussion}

The key output is the braking torque of ECB, which was calculated by integrating the braking torque of the whole disk.

Figure 5 shows the relation between the torque and rotational speed when different numbers of magnets are used. In general, when more magnets are used, the rotational speed and torque are seen to increase linearly, except in the case of the parallel arrangement of 10 magnets (square symbol on the green line). In particular, the cases of four and six magnets show no difference between their different magnet arrangements, but this difference is seen for the cases of eight and ten magnets. Furthermore, a torque of ten 
parallel magnets is lower than that of eight magnets. In the range of rotational speed covered in this study, no critical speed is observed.

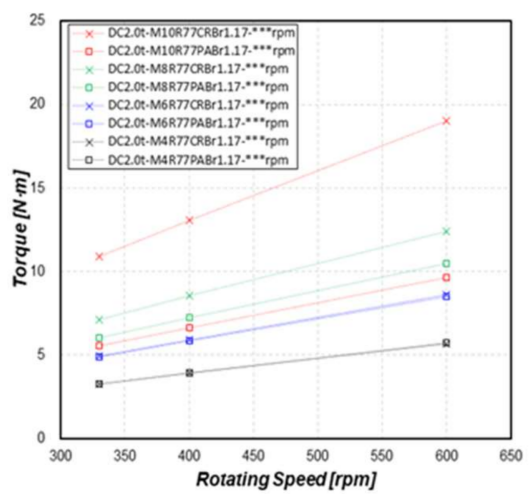

(a) $\mathrm{t}=2.0 \mathrm{~mm}$

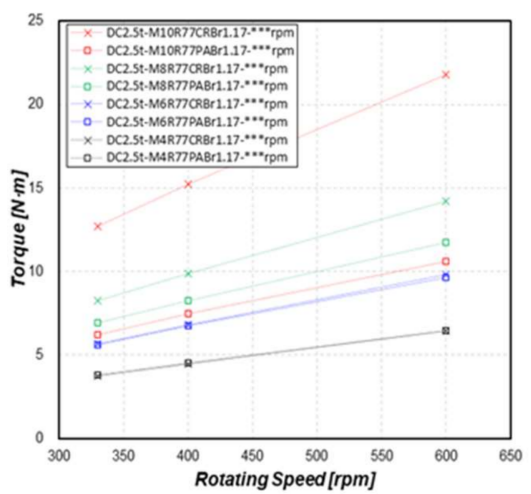

(b) $\mathrm{t}=2.5 \mathrm{~mm}$

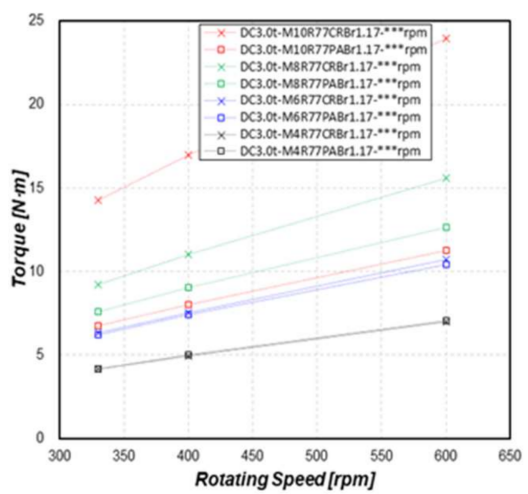

(c) $\mathrm{t}=3.0 \mathrm{~mm}$

Figure 5. Torque vs. rotational speed plot.

Figure 6 prominently shows the differences between the cross and parallel arrangements. In the former case, the braking torques of ECBs progressively increase with the number of magnets. However, for the latter, the torques of four and six magnets are similar, but the rate of increase and decrease in torque when the number of magnets increase from six to eight and finally to ten is lower than that when eight magnets are used. This propensity is affected by distributions of current density in the disks (see Figure 7).

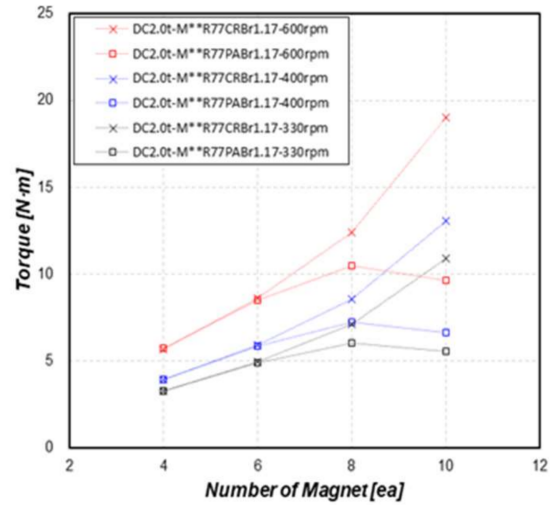

(a) $\mathrm{t}=2.0 \mathrm{~mm}$

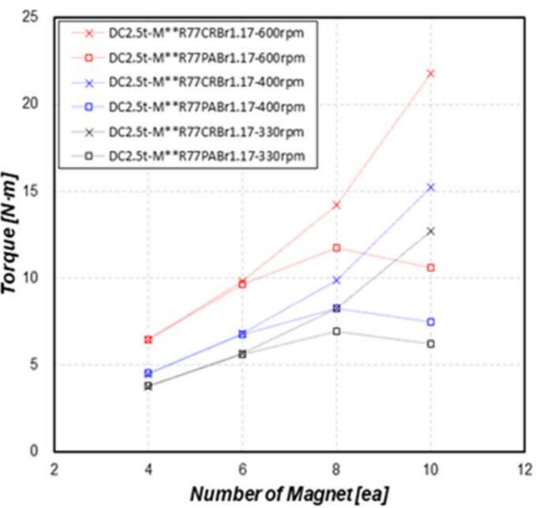

(b) $\mathrm{t}=2.5 \mathrm{~mm}$

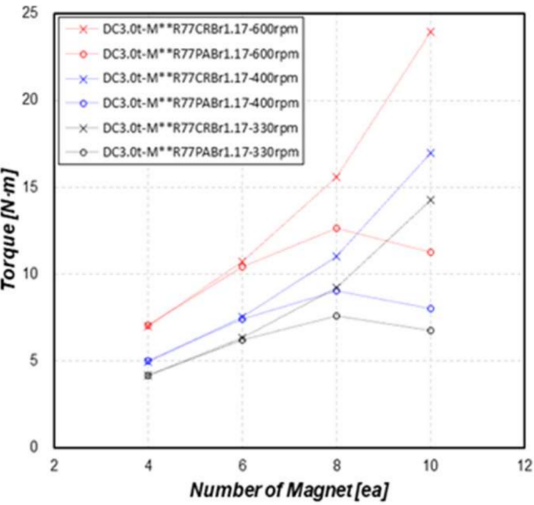

(c) $\mathrm{t}=3.0 \mathrm{~mm}$

Figure 6. Torque vs. number of magnets plot.

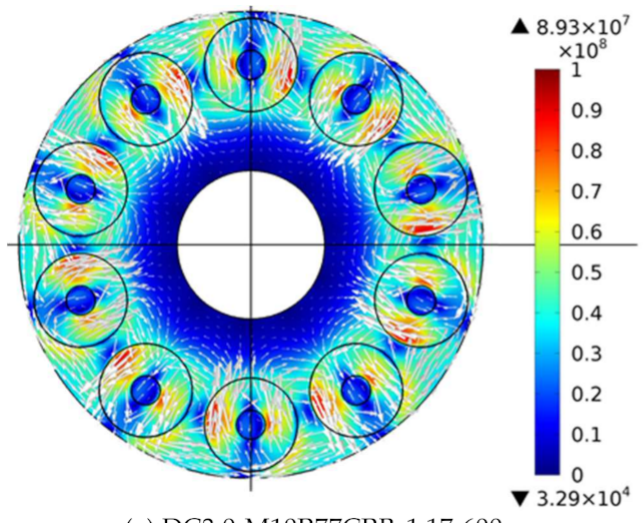

(a) DC3.0-M10R77CRBr1.17-600rpm

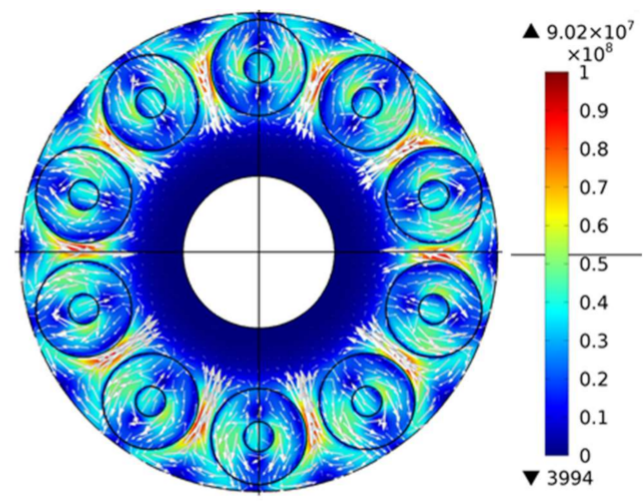

(b) DC3.0-M10R77PABr.1.17-600rpm

Figure 7. Distribution of current density $\left[\mathrm{A} / \mathrm{m}^{2}\right]$. 
Figure 7 shows the cross-arrangement case of disk thickness of $3 \mathrm{~mm}$ and 10 magnets at 600 RPM, whereas Figure $7 \mathrm{~b}$ shows the parallel case under the same conditions. The maximum current density of both is about $9.0 \times 10^{7} \mathrm{~A} / \mathrm{m}^{2}$, but the proportion of the higher current of the cross arrangement is more than that of the parallel arrangement. This is interconnected with the paths of current and the cross-section area of current. First, in the cross-arrangement case, the current paths form large loops over each of two magnets with wider widths, and the higher current density is spread widely in the area under the magnets. If the number of magnets installed increases such that the distance between magnets decreases, the electrical resistance also decreases; therefore, the current and braking torque increases geometrically.

However, in the parallel-arrangement case, the current loops are formed over half magnets and the higher density current passes along the path formed between the magnets. When few magnets are used, the path between the magnets is wide, which has the least impact on the current. However, when the number of magnets installed increases, this effect becomes significant; thus, the overall current density is lowered.

Consequently, the cross arrangement is advantageous, particularly, if sufficient space is unavailable.

Additionally, the results of the magnetic flux density and radial position of magnets are presented in Figures 8 and 9, respectively. These case studies were carried out to assess how to achieve the aim of the research project, the braking torque of $160 \mathrm{~N} \cdot \mathrm{m}$.

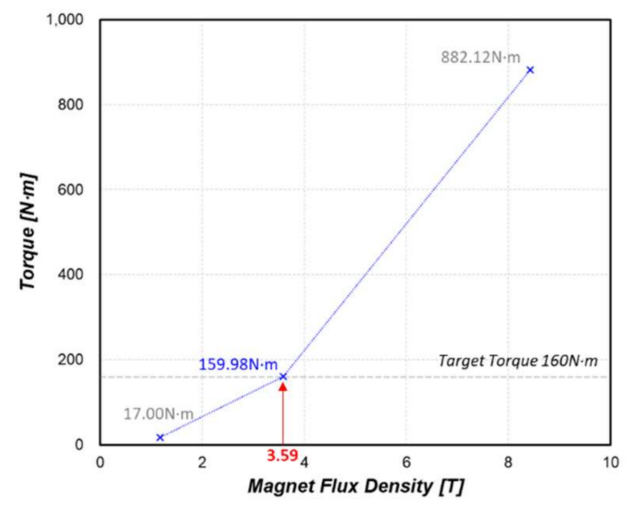

Figure 8. Torque vs. magnetic flux density plot.

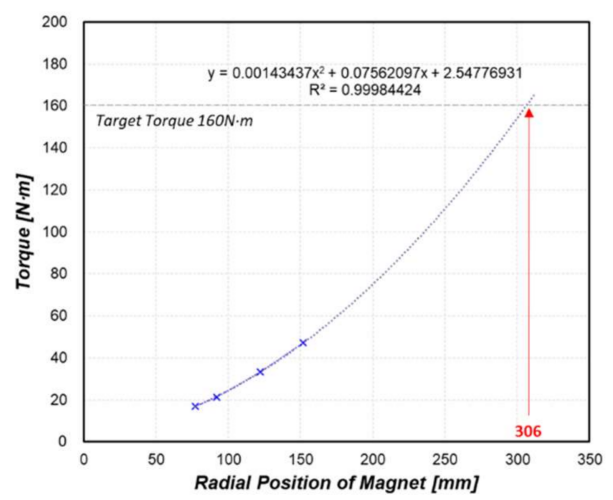

Figure 9. Torque vs. radial position of magnets plot.

Figure 8 shows the braking torques at 1.17, 3.59, and $8.43 \mathrm{~T}$ magnet flux densities for the case of DC3.0t-M10R77CRBr ${ }^{* * *}$-400rpm, which shows a second-order polynomial relationship, which is also seen in the variation of the braking torque with the radial positions of magnets (Figure 9). These results are similar as compared with other equations for calculating the braking torque of ECBs. However, the higher magnetic flux density of $1.17 \mathrm{~T}$ cannot be achieved by permanent magnets; thus, introducing an electromagnet is 
required. However, this decreases the efficiency of the power generation system, which contradicts the initial goal.

Figure 9 shows the braking torques of the cases of 77, 92, 112, and $152 \mathrm{~mm}$ radial magnet positions under the DC3.0t-M10 $\mathrm{R}^{* * *} \mathrm{CRBr} 1.17-400 \mathrm{rpm}$ condition. The target torque is shown at the radial position of $306 \mathrm{~mm}$ by the second-order trend line of these points. In this work, additional simulations were not conducted, because the ECB of the radius is restricted to about $170 \mathrm{~mm}$ by the initial simulation domain (Figure 2). For reliability of the trend line, more data points are required. However, considering both increasing the linear velocity related by larger radial position and the radial position of the torque definition, the second-order trend line of the braking torque to the radial position of the magnets is regarded as appropriate.

Simulations and analyses for cases of larger radial positions with higher magnetic flux density were not conducted in this work, because those cases were not required by limits of permanent magnet flux density and domain size as previously stated.

\section{Conclusions}

The objective of this study was to carry out a parametric study for pre-designing ECBs applicable to small-scale wind power generators. A series of simulations were conducted using the magnetic and electric field modules in COMSOL Multiphysics, and the effects of six different parameters on the ECB were assessed. The disk thickness and rotational speed are linearly proportional to the braking torque, and in the range of rotational speed covered in this study, no critical speed is observed. The radial location of magnets from the center of the disk and magnetic flux density have second-order polynomial relationships with the braking torque. Finally, the number of magnets installed and magnet pole arrangements can significantly affect the performance curve of ECBs. This is caused due to the path of the generated eddy currents.

Author Contributions: Conceptualization, H.J. (Huiseop Jeong) and H.J. (Hoseong Ji); methodology, H.J. (Huiseop Jeong) and H.J. (Hoseong Ji); software, S.C.; validation, H.J. (Huiseop Jeong) and H.J. (Hoseong Ji); formal analysis, H.J. (Huiseop Jeong); investigation, H.J. (Huiseop Jeong) and H.J. (Hoseong Ji); resources, S.C.; data curation, H.J. (Huiseop Jeong) and H.J. (Hoseong Ji); verification experiment, J.B.; writing—original draft preparation, H.J. (Huiseop Jeong); writing—review and editing, H.J. (Huiseop Jeong) and H.J. (Hoseong Ji); visualization, H.J. (Huiseop Jeong); supervision, H.J. (Hoseong Ji); project administration, H.J. (Hoseong Ji); funding acquisition, H.J. (Hoseong Ji). All authors have read and agreed to the published version of the manuscript.

Funding: This work was supported by the Energy Core Technology Program of the Korea Institute of Energy Technology Evaluation and Planning (KETEP), which was granted financial resources from the Ministry of Trade, Industry and Energy, Republic of Korea (No. 20183030029120). And this work was partially supported by the Technology Information Promotion Agency (TIPA) grant funded by the Korean government (MISS) through the Start-up Growth Technology Development Project(S2610394).

Institutional Review Board Statement: Not applicable.

Informed Consent Statement: Not applicable.

Data Availability Statement: Not applicable.

Acknowledgments: Not applicable.

Conflicts of Interest: The authors declare no conflict of interest.

\section{References}

1. Sokolov, G. Analysis of Electrodynamic Brake for Utilization in Systems with Rotating Shafts. Bachelor's Thesis, Saimaan ammattikorkeakoulu, South Karelia, Finland, 2016.

2. Koswatta, A.; Yasusi, S.; Tamaki, S.; Alsharif, F; Tamura, J. Power Analysis of Eddy Current Brake System Applied on Small-Scaled Wind Turbine for dc Greenhouse. In Proceedings of the International Conference on Intelligent Informatics and BioMedical Sciences (ICIIBMS), Shanghai, China, 21-24 November 2019; IEEE Publications: Piscataway, NJ, USA, 2019; pp. 105-109. 
3. Jee, I.H.; Nahm, S.Y.; Kang, S.J.; Ryu, K. A Magnetic Brake for Small Wind Turbines. J. Magn. 2012, 17, 33. [CrossRef]

4. Kramer, V. Design and Development of an Innovative Controller for Small Wind Turbines. Ph.D. Thesis, University of Huddersfield, Huddersfield, UK, 2016.

5. Davies, E.J. An Experimental and Theoretical Study of Eddy-Current Couplings and Brakes. IEEE Trans. Power Apparatus Syst. 1963, 82, 401. [CrossRef]

6. Gonen, D.; Stricker, S. Analysis of an Eddy-Current Brake. IEEE Trans. Power Appar. Syst. 1965, 84, 357. [CrossRef]

7. Smythe, W.R. On Eddy Currents in a Rotating Disk. Electr. Eng. 1942, 61, 681. [CrossRef]

8. Schieber, D. Braking Torque on Rotating Sheet in Stationary Magnetic Field. Proc. Inst. Electr. Eng. UK 1974, 121, 117. [CrossRef]

9. Gosline, A.H.C.; Hayward, V. Eddy Current Brakes for Haptic Interfaces: Design, Identification, and Control. IEEE ASME Trans. Mechatron 2008, 13, 669. [CrossRef]

10. Wouterse, J.H. Critical Torque and Speed of Eddy Current Brake with Widely Separated Soft Iron Poles. IEE Proc. B Electr. Power Appl. UK 1991, 138, 153. [CrossRef]

11. Tatis, K.V.; Kladas, A.G.; Tegopoulos, J.A. Geometry Optimization of Solid Rotor Eddy Current Brake by Using Sensitivity Analysis and 3D Finite Elements. J. Mater. Process. Technol. 2005, 161, 363. [CrossRef]

12. Srivastava, R.K.; Kumar, S. An Alternative Approach for Calculation of Braking Force of an Eddy-Current Brake. IEEE Trans. Magn. 2009, 45, 150. [CrossRef]

13. Shin, H.J.; Choi, J.Y.; Cho, H.W.; Jang, S. Analytical Torque Calculations and Experimental Testing of Permanent Magnet Axial Eddy Current Brake. IEEE Trans. Magn. 2013, 49, 4152. [CrossRef]

14. Caldwell, N.J.; Taylor, J.R.M. Eddy-Current Actuator for a Variable Pitch Air Turbine. In Proceedings of the Third European Wave Energy Conference, Patras, Greece, 1 January 1998; pp. 104-110.

15. Rodrigues, O.; Taskar, O.; Sawardekar, S.; Clemente, H.; Dalvi, G. Design \& Fabrication of Eddy Current Braking System. Int. Res. J. Eng. Technol. 2016, 3, 809-815. 